\title{
CDK5RAP2 primary microcephaly is associated with hypothalamic, retinal and cochlear developmental defects
}

\author{
Hala Nasser, ${ }^{1,2}$ Liza Vera, ${ }^{3}$ Monique Elmaleh-Bergès, ${ }^{4}$ Katharina Steindl, ${ }^{5}$ \\ Pascaline Letard, 1,6,7,8 Natacha Teissier, ${ }^{6,9}$ Anais Ernault, ${ }^{1}$ Fabien Guimiot, ${ }^{6,10}$ \\ Alexandra Afenjar, ${ }^{11}$ Marie Laure Moutard, ${ }^{12}$ Delphine Héron, ${ }^{13}$ Yves Alembik, $^{14}$ \\ Martha Momtchilova, ${ }^{15}$ Paolo Milani, ${ }^{16}$ Nathalie Kubis, ${ }^{16}$ Nathalie Pouvreau, ${ }^{1}$

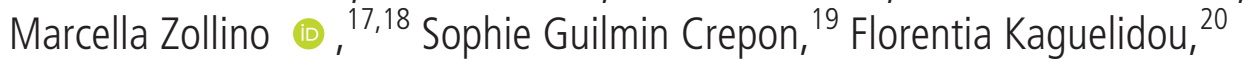 \\ Pierre Gressens, ${ }^{6,21}$ Alain Verloes, 1,6,22 Anita Rauch (1) , ${ }^{5}$ Vincent El Ghouzzi, ${ }^{6}$ \\ Severine Drunat, ${ }^{1,6,22}$ Sandrine Passemard (D) 1,6,22,23
}

- Additional material is published online only. To view, please visit the journal online (http://dx.doi.org/10.1136/ jmedgenet-2019-106474).

For numbered affiliations see end of article.

Correspondence to Dr Sandrine Passemard, Genetic Department, Hopital Robert Debré, APHP, Paris, France; sandrine.passemard@aphp.fr

LV and ME-B contributed equally.

Received 5 August 2019 Revised 22 November 2019 Accepted 29 November 2019 Published Online First 3 February 2020
Check for updates

(C) Author(s) (or their employer(s)) 2020. No commercial re-use. See rights and permissions. Published by BMJ.

To cite: Nasser $H$, Vera L,

Elmaleh-Bergès $\mathrm{M}$, et al.

$J$ Med Genet

2020;57:389-399.

\section{ABSTRACT}

Background Primary hereditary microcephaly (MCPH) comprises a large group of autosomal recessive disorders mainly affecting cortical development and resulting in a congenital impairment of brain growth. Despite the identification of $>25$ causal genes so far, it remains a challenge to distinguish between different MCPH forms at the clinical level.

Methods 7 patients with newly identified mutations in CDK5RAP2 (MCPH3) were investigated by performing prospective, extensive and systematic clinical, MRI, psychomotor, neurosensory and cognitive examinations under similar conditions.

Results All patients displayed neurosensory defects in addition to microcephaly. Small cochlea with incomplete partition type II was found in all cases and was associated with progressive deafness in 4 of them. Furthermore, the CDK5RAP2 protein was specifically identified in the developing cochlea from human fetal tissues. Microphthalmia was also present in all patients along with retinal pigmentation changes and lipofuscin deposits. Finally, hypothalamic anomalies consisting of interhypothalamic adhesions, a congenital midline defect usually associated with holoprosencephaly, was detected in 5 cases.

Conclusion This is the first report indicating that CDK5RAP2 not only governs brain size but also plays a role in ocular and cochlear development and is necessary for hypothalamic nuclear separation at the midline. Our data indicate that CDK5RAP2 should be considered as a potential gene associated with deafness and forme fruste of holoprosencephaly. These children should be given neurosensory follow-up to prevent additional comorbidities and allow them reaching their full educational potential.

Trial registration number NCT01565005.

\section{INTRODUCTION}

Primary microcephaly (PM) is a rare neurodevelopmental disorder characterised by congenital microcephaly, intellectual disability of variable severity
(ID) and occasional epilepsy that may reflect cortical mantle defects. ${ }^{1-3}$

Clinically, PM includes isolated PM (MicroCephaly Primary Hereditary (MCPH), PM with short stature (Seckel syndrome, microcephalic primordial dwarfism) and syndromic PM (associated with non-neurodevelopmental manifestations). $\mathrm{MCPH}$ and Seckel syndrome may be further subdivided by the presence of cortical malformations and/or chorioretinopathy. Although this classification helps managing the differential diagnosis of the patients, it does not reflect underlying mechanisms. Most PMs show autosomal recessive inheritance, ${ }^{13}$ although dominant forms have occasionally been described $^{4-6}$ and a mitochondrial origin has been proposed. ${ }^{7}$ To date, $>100$ genes have been implicated in PM. ${ }^{8}$

The cyclin-dependent kinase 5 (CDK5) regulatory subunit associated protein-encoding gene (CDK5RAP2; OMIM 608201) is among the first genes initially identified in PM (MCPH3, OMIM 604804). ${ }^{9}$ CDK5RAP2 regulates CDK5 activity required for centrosome cohesion, ${ }^{10}$ centriole duplication and attachment of the centrosome to the spindle pole, ${ }^{11}$ and plays a role in microtubule plus-end dynamics. ${ }^{12}$ In addition, it is essential for DNA damage response. ${ }^{13}$ In the developing mouse neocortex, Cdk5rap2 is crucial for the maintenance of apical neural progenitors ${ }^{14} 15$ as its deficiency leads to spindle orientation defects, premature cell cycle exit and increased cell death during neurogenesis, resulting in a reduction in the final neuron number. ${ }^{15}$ During human neurogenesis, CDK5RAP2 is widely expressed in the ventricular and subventricular zones at the weeks of gestation WG12,WG18 and in the superficial layers of the neocortex until term. ${ }^{16}$

Variants in CDK5RAP2 were first identified in association with PM in 2005. ${ }^{9}$ Since then, 35 patients from 17 families have been described, essentially through single case or mutation reports, and with limited clinical details. ${ }^{9}{ }^{17-29}$ Most mutations reported are nonsense or frameshift variants 
(ie, null variants), except for three siblings carrying missense variants $^{22}$ (figure 1 and online supplementary table 1 ). Patients with pathogenic variants in CDK5RAP2 display heterogeneous phenotypes: the first 11 patients reported are microcephalic individuals (Occipitofrontal circumference OFC from -4 to -9 SD during childhood) with normal stature and mild-to-moderate ID. ${ }^{9} 1826$ Three infants were reported with PM and mildly short stature (from -2.5 to $-4 \mathrm{SD}$ ) that corrected with age. Three additional patients from two pedigrees were reported with Seckel-like microcephalic dwarfism. ${ }^{29}$ Feeding difficulties, ${ }^{9} 202426$ skin areas of hypopigmentation ${ }^{9}$ and/or hyperpigmentation, ${ }^{21} 29$ seizures $^{9}$ and deafness 9212629 have been reported. CDK5RAP2 variants have also been reported in patients with corpus callosum agenesis without microcephaly. ${ }^{22}$ One patient developed acute lymphoblastic leukaemia. ${ }^{9}$ This heterogeneity is not supported by any genotype/phenotype correlation and the possibility of additional recessive or de novo mutation has not been ruled out.

Despite this range of presentations, MRI data are lacking. Brain MRI performed in CDK5RAP2 patients have failed to provide specific information. When available, data only indicate a reduced brain size and a qualitative impression of gyral simplification, ${ }^{232628} 29$ similar to reports in other MCPH. ${ }^{30}$ Hypoplasia, agenesis or dysplasia of the corpus callosum have been occasionally reported. ${ }^{2122} 24$ As MRI data have not been reported for the majority of patients, the possibility that CDK5RAP2 patients have specific brain or cortical malformations cannot be ruled out.

Furthermore, no systematic neuropsychological assessment of the patients has been published. Mild-to-moderate ID was reported in the first cases. ${ }^{9}{ }^{20}{ }^{31}$ However, this finding has been challenged by more recent studies using neuropsychological assessments ${ }^{26} 28$ surprisingly showing that individuals with CDK5RAP2 variants have a normal/borderline IQ. Hence, the severe reduction in brain volume in patients with CDK5RAP2 variants does not appear to result in an equally severe impact on cognitive functions. There is thus an urgent need for reliable data on cognitive prognosis in $\mathrm{MCPH}$ as a prerequisite for genetic counselling, adequate educational therapy and medical follow-up.

Here, we took advantage of a cohort of seven new CDK5RAP2 patients, the largest series reported so far, to revisit the phenotype associated with CDK5RAP2 by performing prospective, extensive and systematic clinical, MRI, psychomotor, neurosensory and cognitive examinations under similar conditions. We report four novel and four recently described CDK5RAP2 mutations ${ }^{7}$ and show that, in addition to PM, all patients have skin pigmentation changes as well as congenital neurosensory defects, including microphthalmia and retinal pigmentation defects, and a unique cochlear malformation. In agreement with this latter finding, immuno-labelling on human fetal tissues identifies the CDK5RAP2 protein in the developing cochlea, in addition to the fetal brain. Moreover, five patients exhibit a hypothalamic anomaly. Our data indicate that the CDK5RAP2related phenotype is wider but more homogeneous than previously thought, and that ophthalmic and auditory investigations should be systematically included in the clinical follow-up of these children.

\section{MATERIALS AND METHODS}

\section{Next-generation sequencing or targeted sequencing}

Homozygosity mapping (patients 1 and 2) was performed by SNP array analysis (SurePrint G3 Human Genome CGH+SNP Microarray kit, Agilent Technologies). Coding exons and splice junctions of CDK5RAP2 were sequenced by standard bidirectional Sanger methods. Mutations in patients 3-5 were identified by targeted next-generation sequencing (NGS). CDK5RAP2 was included on a microcephaly gene panel for cohort screening by multiplex PCR enrichment on a microfluidic support (Access Array, Fluidigm) and $2 \times 150$ bp sequencing with an Illumina MiSeq system. Sequencing reads were mapped to the UCSC Genome Browser (hg19) with MiSeq software, the BurrowsWheeler Aligner and the Genome Analysis Toolkit, and panel exons were 99\% covered. Variants were filtered against Mutation Annotation Form (MAF) >0.005, dbSNP, 1000 Genomes, the NHLBI ESP Exome Variant Server and an in-house dataset. Rare variants were annotated for functional features of coding nucleotides with publicly available databases, Polyphen2, SIFT, Mutation taster and Align GVGD. Confirmation of mutations identified by NGS and their familial segregation were carried out (Sanger sequencing). Patients 6 and 7 were part of a wholeexome sequencing study in a larger microcephaly cohort. Methods, sequencing results and few clinical hallmarks of these two patients were reported elsewhere. ${ }^{7}$

\section{Clinical, neuroimaging and neurosensory assessment of the patients}

Seven patients carrying CDK5RAP2 variants identified in Paris or Zurich genetic departments were recruited between 2014 and 2018. Inclusion criteria were: $\mathrm{OFC} \leq-2 \mathrm{SD}$ at birth (WHO growth charts (www.who.int/childgrowth/standards)), no environmental cause of PM. Parents provided informed consent for children's participation.

The protocol included a detailed clinical and neurological examination and the following exams/assessments:

\section{Cerebral MRI}

Included coronal T2-weighted and T1-weighted three-dimensional (3D) sequences with millimetre slices (1.5 T Philips scanner).

\section{Cognitive assessment}

Intellectual abilities were assessed using the international Wechsler scales, according to age (Wechsler Intelligence Scale for Children (WISC) IV: 6-16 years, $n=5$, patients $1,4-7$; Wechsler Preschool and Primary Scale of Intelligence (WPPSI) III: 3-7 years 7 months, $n=2$, patients 2 and 3). Full-Scale IQ (FSIQ) was calculated from four scores for WISC IV: Verbal Comprehension Index (VCI), Perceptual Organisation Index (POI), Working Memory Index (WMI) and Processing Speed Index (PSI). The scores are independent and involve specific cognitive abilities such as lexical stock, general knowledge, verbal comprehension and verbal reasoning (VCI); visuomotor and visuospatial skills to examine a problem, organise thoughts and find solutions using cubes or pictures (POI); short-term memory, concentration abilities, mental manipulation, planning abilities, cognitive flexibility, arithmetic reasoning (WMI) performance speed in graphic realisation and visual discrimination (PSI). FISQ was calculated from three scores for WPPSI III (verbal IQ, performance IQ, and processing speed quotient). Only the non-verbal reasoning scale has been calculated for patient 3 due to language barrier.

\section{Neurosensory assessment}

Ophthalmological assessment included visual acuity measurement with Snellen optotypes axial length measurement, biomicroscopy of the anterior segment and ocular fundus examination. Fundus autofluorescence imaging, full-field scotopic and photopic electroretinograms (ERGs), a pattern-ERG (pERG) and electro-oculography (EOG) were performed in all patients. Two patients underwent optical coherence tomography (3D-OCT). 
Audiological assessment included pure tone and speech audiometry.

Temporal bone high-resolution CT included helical acquisition of submillimetre slices with multiplanar reconstructions (Philips Brilliance 64 CT).

\section{Statistical analysis}

The four scores required to calculate the FSIQ were compared with search for specific learning disorders (one-way analysis of variance and Bonferroni post hoc test). P values $<0.05$ were considered to be statistically significant.

\section{Immunohistology in human fetal cochlea and brain}

Human fetal temporal bone (1) and brain (2) specimen were obtained from morphologically normal miscarried fetuses (WG12 for (1) and WG8 and WG12 for (2)), with the informed written consent of the parents in accordance with French law. Specimen were fixed and paraffin-embedded and immunohistochemistry was performed using antibody against $\gamma$ Tubulin (ab11316, Abcam), Myosin VI (M0691, Sigma) and CDK5RAP2 (A300-554A, Bethyl). Images were acquired using a Confocal Leica SP8.

\section{RESULTS}

\section{Molecular findings}

All CDK5RAP2 mutations are depicted in figure 1, table 1 and online supplementary table 1 .

Homozygosity mapping performed by SNP array analysis revealed a common homozygous locus including CDK5RAP2 in patients 1 and 2 and subsequent Sanger sequencing of CDK5RAP2 revealed a homozygous frameshift duplication of $2 \mathrm{bp}$ in exon 7, leading to a premature stop codon (c.564_565dup, [p.(Lys189Argfs*15)] [GenBank: NM_018249.5] Chr9(GRCh37):g.12 3,298,747_123,298,748dup). Both parents were heterozygous carriers. Gene panel analysis was performed in patients 3-5. Patient 3 was found to carry 'assumed compound-heterozygous' CDK5RAP2 variants, as the parents were not available for testing: one 4 bp deletion in exon 4 (c.217_220del, [p.(Glu73Thrfs*4)] [GenBank: NM_018249.5]; Chr9(GRCh37):g.1 $\left.23313156 \_123313159 \mathrm{del}\right)$ and a $1 \mathrm{bp}$ duplication in exon 36 (c.5495dup, [p.(Leu1832Phefs*3)] [GenBank: NM_018249.5]; Chr9(GRCh37):g.123156873dup). These two variants are predicted to induce a frameshift leading to null alleles. Patients 4 and 5 displayed a homozygous pathogenic mutation in exon 12. This single nucleotide duplication creates a premature stop codon 4 codons downstream (c.1303dup, [p.(Thr435Asnfs*4)] [GenBank: NM_018249.5]; Chr9(GRCh37):g.123280713dup) predicting a null allele. The father was heterozygous carrier (no sample available from the mother).

None of the mutations found in patients 1-3 are present in public databases (gnomAD, dbSNP, 1000 Genomes, the NHLBI Exome Variant Server and the Exome Aggregation Consortium (ExAC) browser). The variant identified in patients 4 and 5 has been reported only once, in the Latino population of the gnomAD database and has never been reported in the homozygous state.

Patients 6 and 7 were found to be compound heterozygous for truncating variants by trio whole-exome sequencing as recently described. ${ }^{7}$ Each patient carried one unreported variant and one with a very low minor allele frequency, both heterozygous, in the ExAC/gnomAD databases. Patient 6 harboured NM_018249.5(CDK5RAP2):c.[558_559delGA]+[c.4441C>T], p. [(Glu186Aspfs*32)]+[(Arg1481*)], Chr9(GRCh37):g.
[123298753 123298754del];[123171568C>T] with the mother heterozygously carrying c. $\left[558 \_559\right.$ delGA $]+[=]$, p. $[(-$ Glu186Aspfs*32)]+[=] (unreported) and the father heterozygously carrying c. $[$ c. $4441 \mathrm{C}>\mathrm{T}]+[=]$, p. $\left[\left(\operatorname{Arg} 1481^{*}\right)\right]+[=]$ (rs587783390; ExAC: $\mathrm{A}=0.00005660 / 4$, no homozygotes). Patient 7 harboured NM 018249.5(CDK5RAP2):c. [3928G > T];[4546G>T] p. $[($ Glu1310*)];[(Glu1516*)] Chr9(GRCh37):g.[123199600C >A];[123171463C>A] with the mother heterozygously carrying c.[4546G $>\mathrm{T}] ;[=]$ p. $[($ Glu1516*)]; $[(=)]$ (rs374351172; ExAC: $A=0.00002472 / 3$, no homozygotes, gnomAD: $A=0.00002844 / 7$, no homozygotes) and the father heterozygously carrying c. [3928G $>\mathrm{T}] ;[=]$ p. $[($ Glu1310*)]; $[(=)]$ (unreported).

\section{Clinical characteristics}

Clinical details are summarised in table 1. Microcephaly was confirmed at birth in all cases and was even detectable during the second or third trimester of pregnancy in five out of seven patients before reaching a mean occipitofrontal circumference (OFC) of $-6 \pm 1.7$ SD during infancy. Nevertheless, an unusual improvement of the OFC after age 2 for patients 1,2 and 4 was noted (online supplementary figure 1 ). None of the patients had short stature beyond age 5. Areas of hypopigmentation or hyperpigmentation of the skin were systematically found in all patients. Motor development was also normal. Suspected around age 3 because of speech delays, the main functional consequence of brain volume reduction and simplified gyri, both obvious on brain MRI (online supplementary figure 2), was ID, ranging from mild to moderate (FSIQ from 40 (patient 5) to 67 (patient 1 ), see online supplementary figure 3 ). We cannot exclude the possibility that patient 5 , with moderate ID may have a second hit related to the context of consanguinity. However, in all patients, a relative preservation of verbal comprehension (VCI 78 and 75 for patients 1 and 2) and visuospatial abilities (71 and 75 for patients 2, 3 and 6) as well as a preservation of mental manipulation was detected (78 and 73 for patients 1 and 4). None of the patients exhibited epilepsy.

\section{Developmental hypothalamic defect}

Patients 1, 2, 4, 5 and 7 displayed interhypothalamic adhesion (IHA), a grey matter band that connects the dorsomedial and ventromedial hypothalamic nuclei and/or arcuate, paraventricular or preoptic nuclei on both sides of the third ventricle ${ }^{32}$ (figure 2). IHA differs from hamartoma as it does not extend into the third ventricle. For patient 6, brain MRI was performed with another protocol including a series of $5 \mathrm{~mm}$ slices without T1-weighted 3D sequence, which did not allow to formally identify IHA. IHA was already noticed on the brain MRI performed at 1 year of age in patient 1 , and was not enhanced after gadolinium injection, as classically described for glioma, another differential diagnosis of IHA. Taken together, these observations suggest that IHA, which is present at least in five out of seven patients, may be caused by a failure of the separation of hypothalamic nuclei at early developmental stages.

\section{Neurosensory impairment}

\section{Microphthalmia and retinal pigmentation defects}

Ophthalmological assessment showed normal biomicroscopy and no oculomotor disorder. The axial length was below the normal range in all patients (average: 20.9, from 20.3 to 22.3 $\mathrm{mm}$; normal age $>3$ years: $23.5 \mathrm{~mm}$ ) (tables 1 and 2 , figures 3 and 4). 
A
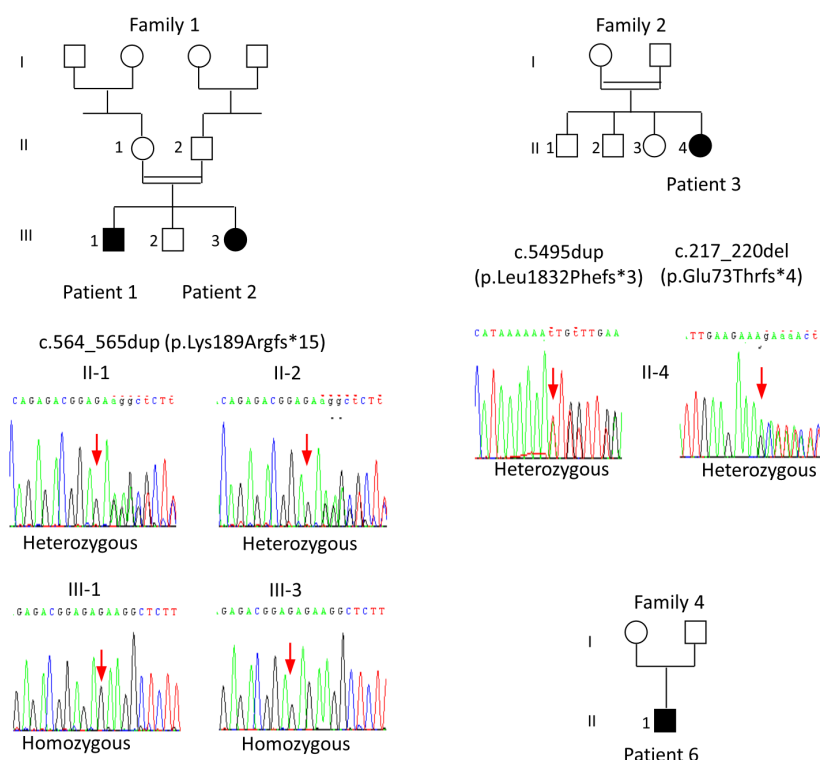

(p.Leu1832Phefs*3) (p.Glu73Thrfs*4)
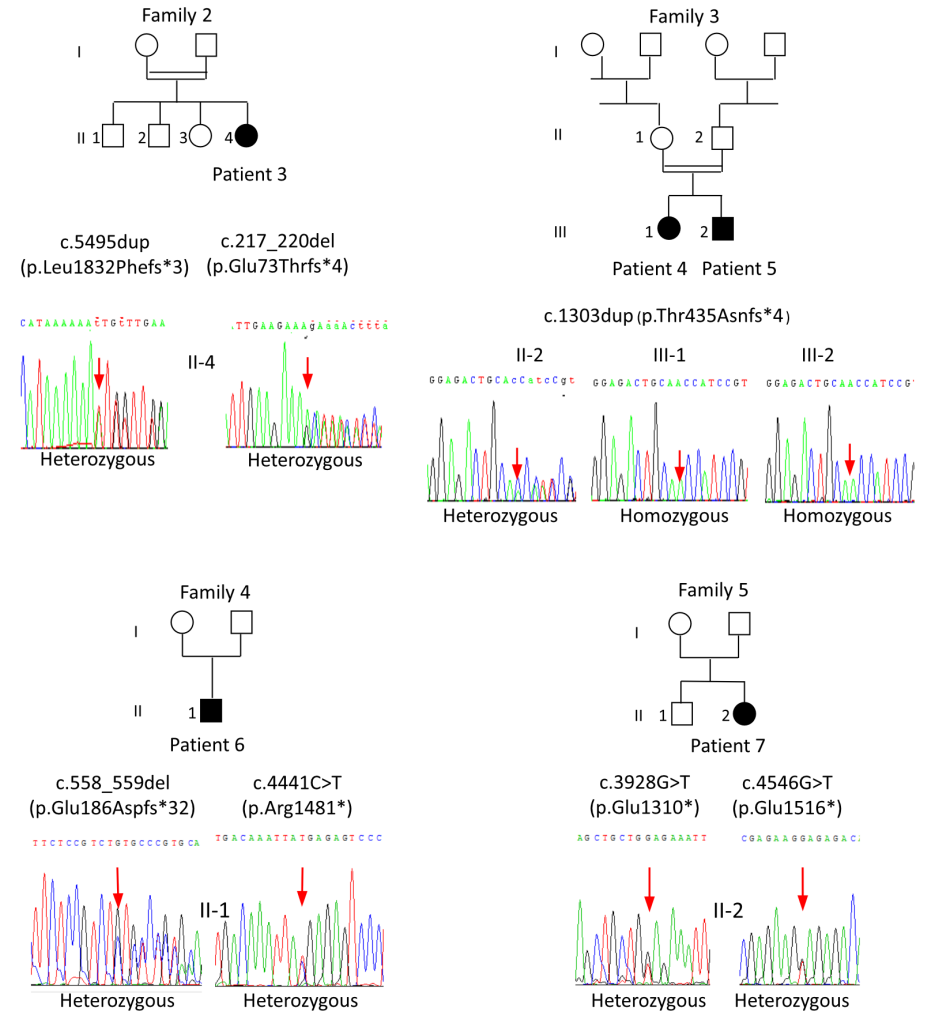

B

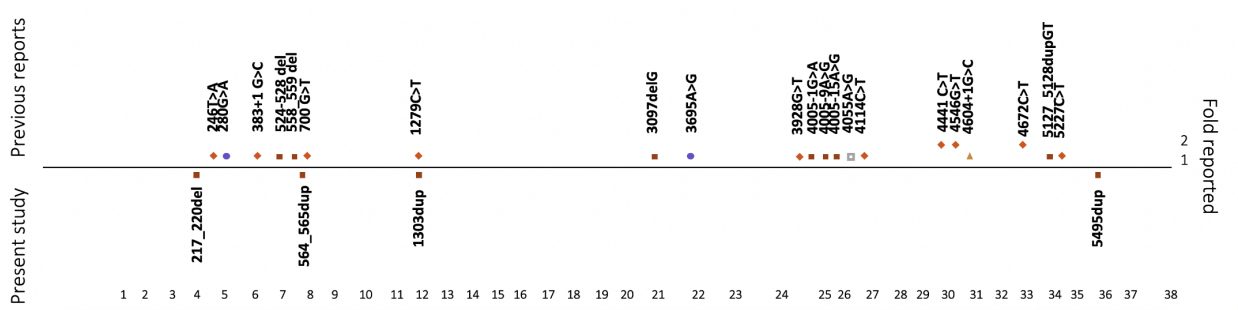

- Missense mutations

A Splice mutations

- Frame shift mutations

- Nonsense mutations

口 Unknown

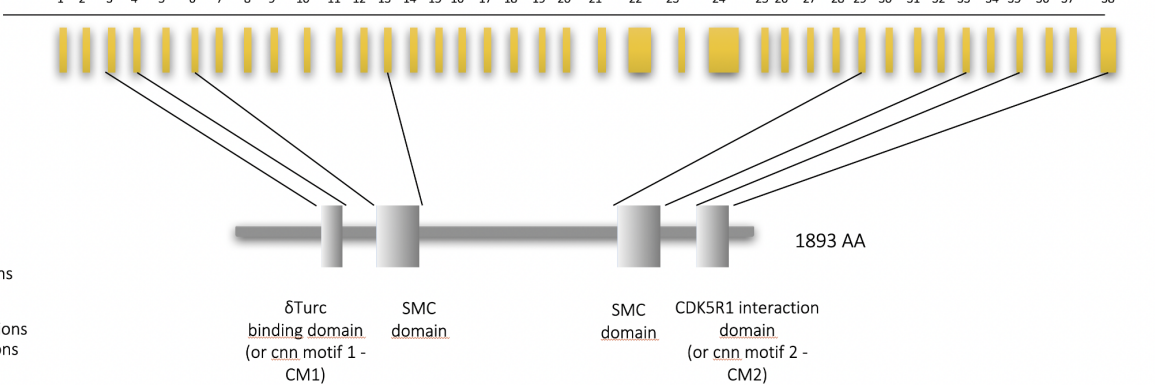

Figure 1 Novel and previously described CDK5RAP2 variants. (A) Pedigree of seven individuals from European (families 2, 4 and 5) or North of Africa's families (families 1 and 3) and their respective Sanger sequencing chromatograms. (B) Scheme representing novel variants in our series and the known variants in the human CDK5RAP2 gene and corresponding domain of the protein. The variants reported previously are shown above the horizontal line; novel variants from the present study are indicated below this line and just above the exons. Various symbols represent missense, nonsense, splice and frameshift variants as indicated. yTuRC, gamma-tubulin ring complex; CM1, centrosomin (cnn) motif 1; SMC, structural maintenance of chromosomes protein.

In all patients, examination of the ocular fundus revealed round or oval regions of focal hyperpigmentation or hypopigmentation scattered in the periphery and all along the vascular arcade. Hyperpigmented lesions consisted of either extended dark grey lesions or small dark lesions scattered in the macular zone and in the retinal periphery (figure 3A-B). Small round spots of hypopigmentation were either located in the macula (figure $3 \mathrm{~B}$ ) or scattered in the periphery (figure $3 \mathrm{~A}-\mathrm{B}$ ). All hyperpigmented lesions were hypoautofluorescent (figure 3C-D), while hypopigmented spots were hyperautofluorescent (figure 3C-D). OCT was performed and found normal in patients 1 and 4 .

All patients being hyperopic, best-corrected visual acuity was 20/20 except in the youngest patient (patient 3), aged 4 years and non-cooperative, whose visual acuity was superior to 20/40 in each eye. Scotopic and photopic flash ERGs as well as the EOG and pERG were similar to age-matched controls (data not shown). 
Table 1 Clinical and molecular findings of patients with CDK5RAP2 mutations

\begin{tabular}{|c|c|c|c|c|c|c|c|}
\hline Family & 1 & 1 & 2 & 3 & 3 & 4 & 5 \\
\hline Subject & Patient 1 & Patient 2 & Patient 3 & Patient 4 & Patient 5 & Patient 6 & patient 7 \\
\hline Gender & $M$ & $F$ & $\mathrm{~F}$ & $\mathrm{~F}$ & M & M & $\mathrm{F}$ \\
\hline CDK5RAP2 variant & $\begin{array}{l}\text { c.564_565dup } \\
\left.\text { (p.Lys189Argfs }{ }^{*} 15\right)\end{array}$ & $\begin{array}{l}\text { c.564_565dup } \\
\text { (p.Lys189Argfs*15) }\end{array}$ & $\begin{array}{l}\text { c.5495dup, } \\
\text { (p.Leu1832Phefs*3) ; } \\
\text { c.217-220del, } \\
\text { (p.Glu73Thrfs } 4 \text { ) }\end{array}$ & $\begin{array}{l}\text { c.1303dup } \\
\text { (p.Thr435Asnfs*4) }\end{array}$ & $\begin{array}{l}\text { c.1303dup } \\
\text { (p.Thr435Asnfs*4) }\end{array}$ & $\begin{array}{l}\text { c.558_559del, } \\
\text { (p.Glu186Aspfs*32) } \\
\text {; c.4441C>T, (p.Arg1481*) }\end{array}$ & $\begin{array}{l}\text { c.3928G >T, (p.Glu1310*) } \\
\vdots \\
\text { c. } 4546 G>T \text {, (p.Glu1516*) }\end{array}$ \\
\hline Ethnic origin & Tunisia & Tunisia & Serbia & Morocco & Morocco & Italian/Romanian & Swiss/Austrian \\
\hline Consanguinity & Yes & Yes & Yes & Yes & Yes & No & No \\
\hline Mother $\mathrm{HC}(\mathrm{cm}, \mathrm{SD})$ & $56(+1)$ & $56(+1)$ & $54.5(0)$ & Not available & Not available & $53 \mathrm{~cm}$ & Not available \\
\hline Father $\mathrm{HC}(\mathrm{cm}, \mathrm{SD})$ & $60(+3.5)$ & $60(+3.5)$ & $57.5(+1.5)$ & Not available & Not available & $58.5 \mathrm{~cm}$ & Not available \\
\hline $\begin{array}{l}\text { Pregnancy duration (weeks of } \\
\text { amenorrhoea) }\end{array}$ & 38 & 40 & 39 & 39 & 38 & 41 & 39 \\
\hline $\begin{array}{l}\text { Prenatally diagnosed microcephaly } \\
\text { (ultrasounds) }\end{array}$ & Third trimester & Second trimester & $\begin{array}{l}\text { Non-reported } \\
\text { microcephaly }\end{array}$ & $\begin{array}{l}\text { Non-reported } \\
\text { microcephaly }\end{array}$ & Third trimester & Second trimester & Third trimester \\
\hline Fetal cranial MRI & Not performed & Not performed & Not performed & Not performed & Not performed & Not available & Not performed \\
\hline Weight at birth (kg, SD) & $2.490(-2)$ & $3.160(-0.5)$ & $2.965(-1)$ & $2.260(-2.5)$ & $1.520(-3.5)$ & $2.900(-1.5)$ & $2.005(-3)$ \\
\hline Length at birth $(\mathrm{cm}, \mathrm{SD})$ & $45(-3.5)$ & $45(-3)$ & $47(-2.5)$ & $45(-3)$ & $41(-5.5)$ & $46(-3)$ & $44(-3)$ \\
\hline $\mathrm{HC}$ at birth (SD) & $31(-2.2)$ & $30.5(-2.5)$ & $30.5(-2.5)$ & $29.5(-3)$ & $26.5(-5)$ & $30.5(-2.5)$ & $28(-4)$ \\
\hline Age at last examination (years) & 10 & 4.5 & 4.5 & 11 & 10 & 8 & 14.5 \\
\hline Weight at last examination (kg, SD) & $52.5(+5.5)$ & $12.5(-2)$ & $19.5(+2)$ & $48.3(+3)$ & $21.5(-2)$ & $26(+0.5)$ & $34.3(-3)$ \\
\hline Length at last examination $(\mathrm{m}, \mathrm{SD})$ & $1.34(0)$ & $0.94(-2)$ & $1.07(+1)$ & $1.44(+0.5)$ & $1.27(-1.5)$ & $118(-1.5)$ & $146.4(-2)$ \\
\hline $\mathrm{HC}$ at last examination $(\mathrm{cm}, \mathrm{SD})$ & $48.5(-3.4)$ & $42(-6.6)$ & $42.5(-6.2)$ & $47.5(-4)$ & $42(-7.7)$ & $42.8 \mathrm{~cm}(-7.2)$ & $43.2(-7.3)$ \\
\hline \multicolumn{8}{|l|}{ Development } \\
\hline Age of walking (months) & 10.5 & 16 & 14 & 11 & 18 & 12 & 18 \\
\hline Mastication (if delayed, age in months) & Delayed (24) & Delayed (24) & Normal & Normal & Delayed (24) & Delayed (30-36) & Normal \\
\hline $\begin{array}{l}\text { Age of first comprehensive words } \\
\text { (months) }\end{array}$ & 18 & 18 & 30 & 24 & 54 & 18 & 21 \\
\hline Age of first sentences (years) & 4.5 & 2 & 4.5 & 3 & $\begin{array}{l}\text { Unvested, severe } \\
\text { articulation disorders }\end{array}$ & 8 & 3.5 \\
\hline Language articulation (normal, delayed) & Normal & Normal & Delayed & Normal & Delayed & Delayed (30 mo) & Delayed \\
\hline Social interaction (normal/delayed) & Normal & Normal & Normal & Normal & Normal & Normal & Normal \\
\hline Years in kinder garden & 3 & 0 & 1 & & & & \\
\hline Elementary school & $\begin{array}{l}\text { First year in normal class, } \\
\text { then home schooling }\end{array}$ & & & & & & \\
\hline Seizures & 0 & 0 & 0 & 0 & 0 & 0 & 0 \\
\hline \multicolumn{8}{|l|}{ Neurological findings } \\
\hline Hypertonia within the first 2 years of life & 0 & 0 & 0 & 0 & 0 & Yes & Yes \\
\hline Hypotonia within the first 2 years of life & 0 & 0 & 0 & 0 & 0 & No & Axial hypotonia \\
\hline Pyramidal syndrome & 0 & 0 & 0 & 0 & 0 & No & 0 \\
\hline Inferior limb spasticity & 0 & 0 & 0 & 0 & 0 & Yes & Yes \\
\hline Ataxia & 0 & 0 & 0 & 0 & 0 & Incoordinate movements & Yes \\
\hline \multicolumn{8}{|l|}{ Behaviour } \\
\hline Hyperactivity & Yes & Yes & Yes & Before $7-8$ years & Before $7-8$ years & $\begin{array}{l}\text { Quiet behaviour, but } \\
\text { hyperactivity episodes }\end{array}$ & No \\
\hline Tic disorders & No & No & No & No & 0 & $\begin{array}{l}\text { (but repetitive } \\
\text { movements) }\end{array}$ & No \\
\hline Agressiveness & No & No & No & No & 0 & Episodes of aggressiveness & No \\
\hline \multicolumn{8}{|l|}{ Intellectual abilities } \\
\hline Total IQ & 62 & 67 & & 40 & 56 & 52 & 46 \\
\hline \multicolumn{8}{|l|}{ Sensorineural anomalies } \\
\hline $\begin{array}{l}\text { Congenital hearing loss (unilateral/ } \\
\text { bilateral) }\end{array}$ & No & No & No & No & No & 0 & No \\
\hline $\begin{array}{l}\text { Progressive hearing loss (uni/bilateral), } \\
\text { age }\end{array}$ & Bilateral, 9 years & No & Unilateral, 7 years & No & Bilateral, 7 years & Bilateral, 10 years & No \\
\hline Hearing (auditory threshold) & $\begin{array}{l}\text { Right: severe deafness } \\
\text { ( } 70-80 \mathrm{~dB}) \\
\text { Left: moderate deafness } \\
(20-50 \mathrm{~dB})\end{array}$ & $\begin{array}{l}\text { Normal oto-acoustic } \\
\text { emissions within the first } \\
\text { months of life }\end{array}$ & $\begin{array}{l}\text { Right: severe deafness } \\
\text { ( } 70 \mathrm{~dB}) \\
\text { Left: normal }\end{array}$ & $\begin{array}{l}\text { Right: normal ( } 15-20 \mathrm{~dB}) \\
\text { Left: normal (15-25 dB) }\end{array}$ & $\begin{array}{l}\text { Right: severe deafness } \\
(80-90 \mathrm{~dB}) \\
\text { Left: severe deafness } \\
(60-70 \mathrm{~dB})\end{array}$ & $\begin{array}{l}\text { Right: severe deafness } \\
\text { (60-80 dB) } \\
\text { Left: moderate-to-severe } \\
\text { deafness ( } 40-60 \mathrm{~dB} / 60-80 \\
\text { dB) }\end{array}$ & Right and left: normal \\
\hline Hearing aid (unilateral/bilateral) & Unilateral & No & Unilateral & No & Bilateral & Bilateral & No \\
\hline $\begin{array}{l}\text { Retinal hypopigmentation (unilateral/ } \\
\text { bilateral) }\end{array}$ & Bilateral & Bilateral & Bilateral & Bilateral & Bilateral & $?$ & Yes \\
\hline $\begin{array}{l}\text { Retinal hyperpigmentation (unilateral/ } \\
\text { bilateral) }\end{array}$ & Bilateral & Bilateral & Bilateral & Bilateral & Bilateral & $?$ & No \\
\hline ERG & Normal & Normal & Normal & Normal & Normal & Not done & Normal \\
\hline \multicolumn{8}{|l|}{ Skin anomalies } \\
\hline Area of hypopigmentation & Yes & Yes & Yes & No & No & No & Yes \\
\hline Area of hyperpigmentation & Yes & Yes & No & Yes & Yes & $\begin{array}{l}\text { Yes (several cafè-au-lait } \\
\text { spots on trunk, arms } \\
\text { and legs) }\end{array}$ & Yes \\
\hline
\end{tabular}




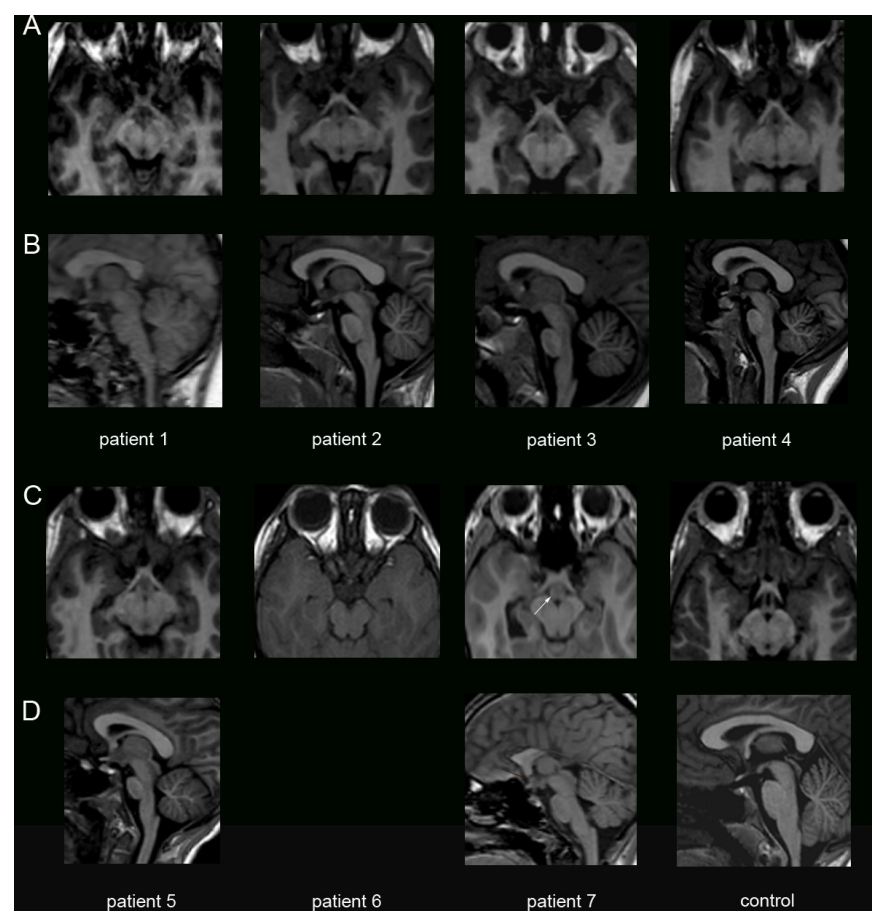

Figure 2 Developmental hypothalamic defects in patients with CDK5RAP2 variants. Coronal $(A, C)$ and sagittal $(B, D) T 1$-weighted images showing in patients $1,2,4,5$ and 7 a structure iso-intense to grey matter consistent with an interhypothalamic adhesion (IHA, white arrows), and absent in the healthy control. This grey matter band on coronal view and nodular on sagittal view is located at the level of the upper midbrain, closed to the anterior/inferior third ventricle. IHA is known to connect both dorsomedial and ventromedial hypothalamic nuclei and/or arcuate, paraventricular or pre-optic nuclei on both sides of the third ventricle.

Progressive hearing loss associated with congenital inner ear malformation

Patients 1, 3, 5 and 6 developed progressive unilateral or bilateral hearing loss, respectively diagnosed at age 9, 6, 7 and 10 (table 1). Audiometric evaluations at diagnosis showed severe hearing loss from 70 to $80 \mathrm{~Hz}$ in at least one ear for all four patients. Patient 1 had a unilateral scotoma of the left ear at $6000 \mathrm{~Hz}$ at $60 \mathrm{~dB}$, and a $77.5 \mathrm{~dB}$ threshold in the right ear (figure 4B-C). Close to normal hearing levels were restored with conventional hearing aids. However, patient 5 did not receive early intervention/rehabilitation. This delayed medical support is likely to have increased the receptive and expressive speech impairment caused by PM itself and worsened ID. Surprisingly, although they had been stable for at least 4 years, patient 1 has recently undergone an improvement of his auditory thresholds, which is now at $42 \mathrm{~dB}$ in the right ear and $26 \mathrm{~dB}$ in the left ear on average, with a concordant vocal threshold.

As sensorineural hearing loss (SNHL) is very unusual in patients with PM, a temporal bone CT scan was performed for all patients except patient 6 (parental rejection), and revealed the same cochlear malformation in each case: small cochlea compared with normal values on $\mathrm{CT}^{33}$ and an absence of the interscalar septa at the apical turn (figure 4A and table 2), that is, compatible with the diagnosis of incomplete partition type II of the Sennaroglu classification. ${ }^{34}$ In addition, patient 2 displayed an enlarged vestibular aqueduct associated with this cochlear dysplasia. In all patients, the diameter of the bony cochlear nerve canal was reduced $(<1.7 \mathrm{~mm})$, in favour of a cochlear nerve hypoplasia. ${ }^{33}$

\section{CDK5RAP2 detection in the fetal cochlear epithelium}

The CDK5RAP2 protein is known to be expressed in the ventricular zone (VZ) of both mouse and human telencephalon throughout neurogenesis. ${ }^{16}$ However, its presence in the inner ear has not been documented so far. Using immunohistochemistry for CDK5RAP2 on human fetal tissues, we found that it is expressed in the developing cochlea in addition to the fetal brain. Co-labelling of CDK5RAP2 with $\gamma$-tubulin on human fetal brain sections at early (WG8) and mild (WG12) stages of neurogenesis confirmed that CDK5RAP2 is highly expressed at the centrosome of the apical radial glial cells (aRGCs) of the $\mathrm{VZ}$ (online supplementary figure 4). Immunolabeling on human

\begin{tabular}{|c|c|c|c|c|c|c|c|c|c|c|c|c|c|c|}
\hline \multirow{2}{*}{$\begin{array}{l}\text { Neuroradiological } \\
\text { findings } \\
\text { Corpus callosum } \\
\text { (CC) }\end{array}$} & \multicolumn{2}{|l|}{$\begin{array}{l}\text { Patient } 1 \\
10 \text { years }\end{array}$} & \multicolumn{2}{|l|}{$\begin{array}{l}\text { Patient } 2 \\
4.5 \text { years }\end{array}$} & \multicolumn{2}{|l|}{$\begin{array}{l}\text { Patient } 3 \\
4.5 \text { years }\end{array}$} & \multicolumn{2}{|c|}{$\begin{array}{l}\text { Patient } 4 \\
11.5 \text { years }\end{array}$} & \multicolumn{2}{|l|}{$\begin{array}{l}\text { Patient } 5 \\
10 \text { years }\end{array}$} & \multicolumn{2}{|l|}{$\begin{array}{l}\text { Patient } 6 \\
5 \text { years }\end{array}$} & \multicolumn{2}{|c|}{$\begin{array}{l}\text { Patient } 7 \\
13.75 \text { years }\end{array}$} \\
\hline & $\begin{array}{l}\text { Raw } \\
\text { measure }\end{array}$ & $\begin{array}{l}\text { 3rd } \\
\text { percentile }\end{array}$ & $\begin{array}{l}\text { Raw } \\
\text { measure }\end{array}$ & $\begin{array}{l}\text { 3rd } \\
\text { percentile }\end{array}$ & $\begin{array}{l}\text { Raw } \\
\text { measure }\end{array}$ & $\begin{array}{l}\text { 3rd } \\
\text { percentile }\end{array}$ & $\begin{array}{l}\text { Raw } \\
\text { measure }\end{array}$ & $\begin{array}{l}\text { 3rd } \\
\text { percentile }\end{array}$ & $\begin{array}{l}\text { Raw } \\
\text { measure }\end{array}$ & $\begin{array}{l}\text { 3rd } \\
\text { percentile }\end{array}$ & $\begin{array}{l}\text { Raw } \\
\text { measure }\end{array}$ & $\begin{array}{l}\text { 3rd } \\
\text { percentile }\end{array}$ & $\begin{array}{l}\text { Raw } \\
\text { measure }\end{array}$ & $\begin{array}{l}\text { 3rd } \\
\text { percentile }\end{array}$ \\
\hline APD (mm) & 45.7 & $(59.1)$ & 47.91 & $(55.5)$ & 42.43 & $(55.5)$ & 55.86 & $(59.7)$ & 49.06 & $(59.1)$ & 30.09 & $(56.2)$ & 29.39 & $(61.7)$ \\
\hline Cranial FOD (mm) & 121.6 & (148.6) & 113.2 & (140.5) & 113 & (140.5) & 130.1 & (145) & 114.5 & (148.6) & 113 & (142.3) & 125 & (147.5) \\
\hline APD/FOD & 0.37 & $(0.37)$ & 0.42 & $(0.36)$ & 0.37 & $(0.36)$ & 0.42 & $(0.37)$ & 0.42 & $(0.37)$ & 0.27 & $(0.36)$ & 0.23 & $(0.38)$ \\
\hline GT (mm) & 9.48 & (7.3) & 7.25 & (6.7) & 7.36 & (6.7) & 8.72 & (7.4) & 7.96 & $(7.3)$ & 6.2 & (6.9) & 7.22 & (7.6) \\
\hline BT (mm) & 7.42 & (4) & 5.39 & (3.5) & 6.93 & (3.5) & 5.46 & (4) & 6.42 & (4) & 7.8 & (3.7) & 5.23 & (3.9) \\
\hline IT (mm) & 7.3 & (2.4) & 4.82 & (1.9) & 6.02 & (1.9) & 6.14 & (2.4) & 6.32 & (2.4) & 6 & (2) & 4.6 & (2.5) \\
\hline ST (mm) & 9.09 & (7.7) & 10.02 & (6.7) & 8.11 & (6.7) & 11.17 & $(7.7)$ & 10.13 & (7.7) & 3.9 & (6.9) & 0 & (7.1) \\
\hline Gyration & \multicolumn{2}{|l|}{ Simplified } & \multicolumn{2}{|l|}{ Simplified } & \multicolumn{2}{|l|}{ Simplified } & \multicolumn{2}{|l|}{ Simplified } & \multicolumn{2}{|l|}{ Simplified } & \multicolumn{2}{|l|}{ Simplified } & \multicolumn{2}{|l|}{ Simplified } \\
\hline $\begin{array}{l}\text { Interhypothalamic } \\
\text { adhesions }\end{array}$ & \multicolumn{2}{|l|}{ Yes } & \multicolumn{2}{|l|}{ Yes } & \multicolumn{2}{|l|}{ No } & \multicolumn{2}{|l|}{ Yes } & \multicolumn{2}{|l|}{ Yes } & \multicolumn{2}{|c|}{$\begin{array}{l}? \\
\text { Midline sagittal } \\
\text { sections }>5 \mathrm{~mm}\end{array}$} & \multicolumn{2}{|l|}{ Yes } \\
\hline Internal ear & \multicolumn{2}{|c|}{$\begin{array}{l}\text { Type II incomplete } \\
\text { partition of the cochlea }\end{array}$} & \multicolumn{2}{|c|}{$\begin{array}{l}\text { Type II incomplete } \\
\text { partition of the cochlea } \\
\text { Enlarged right } \\
\text { vestibular aqueduct }\end{array}$} & \multicolumn{2}{|c|}{$\begin{array}{l}\text { Type II incomplete } \\
\text { partition of the } \\
\text { cochlea }\end{array}$} & \multicolumn{2}{|c|}{$\begin{array}{l}\text { Type II incomplete } \\
\text { partition of the cochlea }\end{array}$} & \multicolumn{2}{|c|}{$\begin{array}{l}\text { Type II incomplete } \\
\text { partition of the } \\
\text { cochlea }\end{array}$} & \multicolumn{2}{|c|}{ Not performed } & \multicolumn{2}{|c|}{$\begin{array}{l}\text { Type II incomplete } \\
\text { partition of the cochlea }\end{array}$} \\
\hline
\end{tabular}

Adapted from Garel et al, 2011. ${ }^{50}$ 

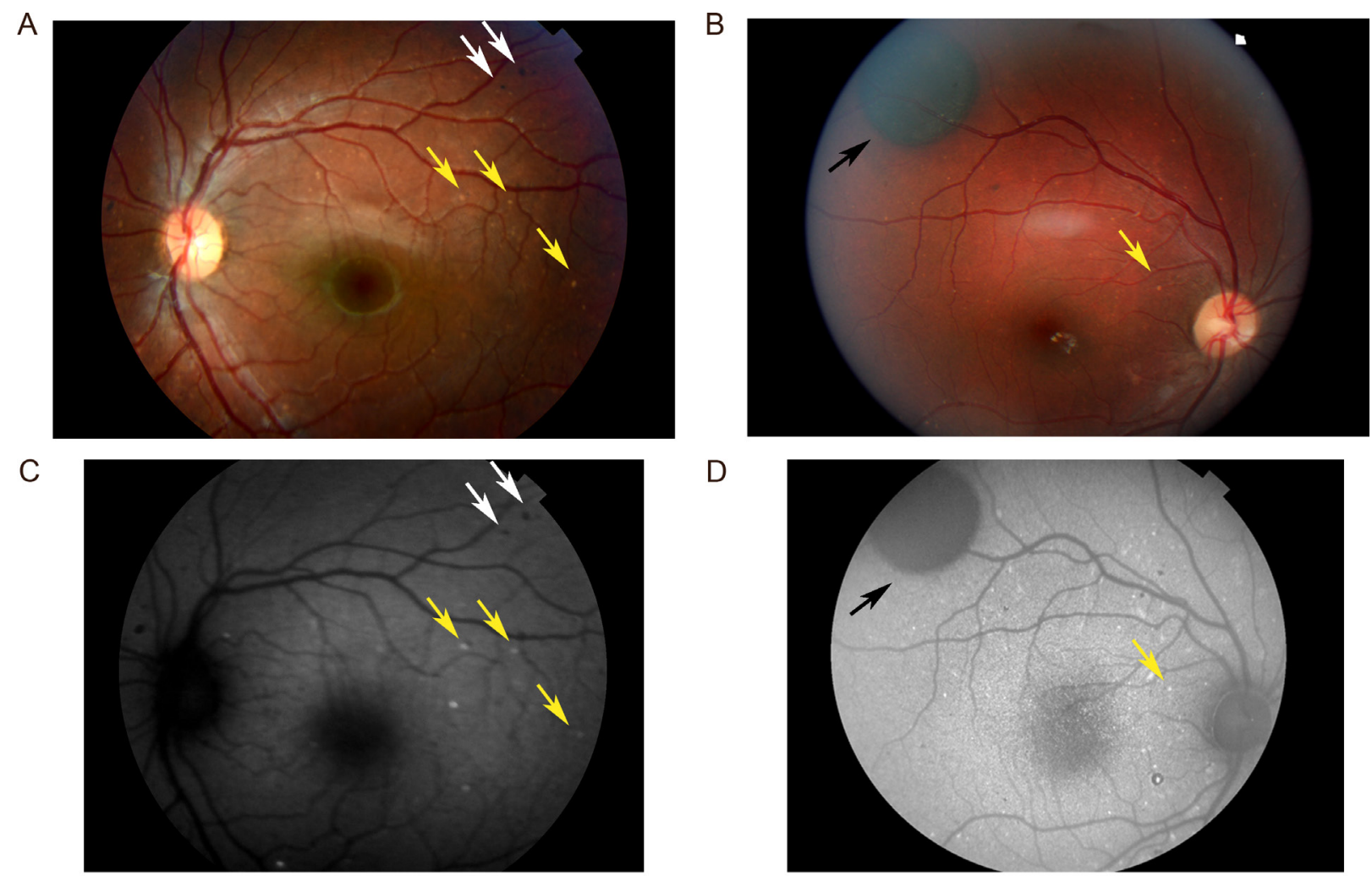

$\mathrm{D}$

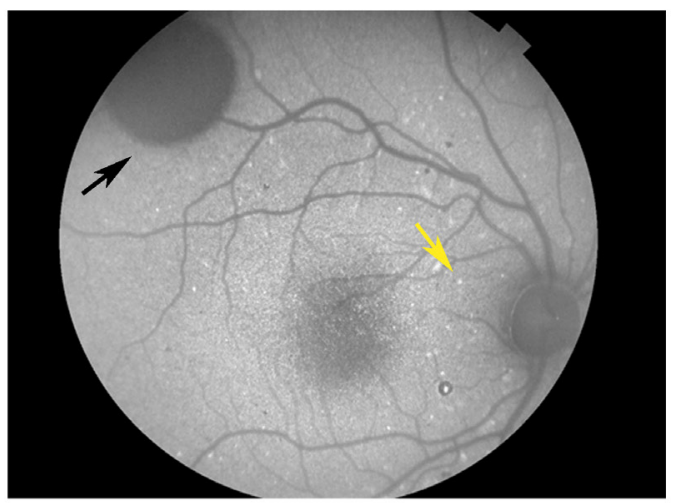

Patient 1

Patient 4

Figure 3 Retinal pigmentary changes in patients with CDK5RAP2 variants. (A, B) Ocular fundus photography of patients 1 and 4 showing focal regions of hyperpigmentation and hypopigmentation in the retinal pigment epithelium (RPE). Note that hyperpigmented lesions appeared as small dark spots (patient 1, white arrows) or dark grey extended lesions (patient 4, black arrow) and were located in the macular zone and/or in the retinal periphery. Small round spots of hypopigmentation were scattered in the posterior pole (yellow arrows in patients 1 and 4). (C, D) Ocular fundus autofluorescence showing that hyperpigmented lesions appear as well-defined patches of hypoautofluorescence (figure $3 C-D$, white and black arrows), whereas hypopigmented spots appear as areas of hyperfluorescence, reminiscent of lipofuscin deposits/accumulation in the RPE in both patients (yellow arrows).

fetal cochlea at WG12 showed that CDK5RAP2 is expressed in MYOSIN VI (a protein expressed in the cytoplasm of outer hair cells of the organ of Corti) positive cells (figure 4F (and Figure 4 D-E for low magnification). At the apical pole of these outer hair cells, CDK5RAP2 was also co-expressed with $\gamma$-tubulin (figure 4G) at the centrosome, concordant with its expression within the VZ. Thus, CDK5RAP2 is expressed early at the centrosome in the sensory epithelium of the organ of Corti as in the neuroepithelium.

\section{DISCUSSION}

In this study, we identify neurosensory impairments associated with the CDK5RAP2 microcephaly, including retinal pigmentation defects and a specific cochlear malformation responsible for progressive sensorineural hearing loss. All patients examined with our protocol displayed IHA, suggesting a failure in hypothalamic nuclei separation. CDK5RAP2 is thus crucial for neurosensory development in addition to brain development.

\section{CDK5RAP2 and brain development}

In agreement with the congenital defects observed, CDK5RAP2 is highly expressed during human neurocorticogenesis. Although the protein has been detected from WG18 onwards, ${ }^{16}$ we find that CDK5RAP2 is present as early as WG8 in the VZ of the human fetal cortex, at the centrosome of aRGCs. This highlights CDK5RAP2 requirement for early progenitors' division and may explain why microcephaly is often detected antenatally.
Similarly, aRGCs switch from symmetric (proliferative) to asymmetric (neurogenic) division in Cdk5rap2-deficient mice, which results in premature cell cycle exit, increased cell death and a reduced number of cortical neurons. ${ }^{15}$

Interestingly, OFC suddenly increased after age 2 in three patients (online supplementary figure 1), a phenomenon not previously reported in PM. The partial compensation observed could result from postnatal white matter development, myelination and/or synaptogenesis. ${ }^{35} 36$ Brain MRI early follow-up, including T2-weighted images and tractography should therefore be envisioned to assess myelination and synaptogenesis in CDK5RAP2 patients. Despite the reduction in neuron number, it is possible that neurons that have reached maturity manage developing a fairly efficient network, a situation that would be consistent with the mild ID observed, unlike patients with PM due toASPM mutations who have more pronounced ID. ${ }^{30}$ In agreement with this assumption, patients whose OFC increases after age 2 also showed a higher IQ. Larger cohorts would greatly help validating this hypothesis.

IHA was detected in five patients. This band of grey matter connects hypothalamic nuclei from the two sides of the third ventricle may be similar to a forme fruste of holoprosencephaly (HPE), which is restricted to the ventral part of the diencephalon and characterised by the non-separation of hypothalamic nuclei along the midline without fusion of the thalami. IHA is often associated with other CNS midline defects including corpus callosum dysgenesis, as seen in patients 6 and 7, or other defects 
A
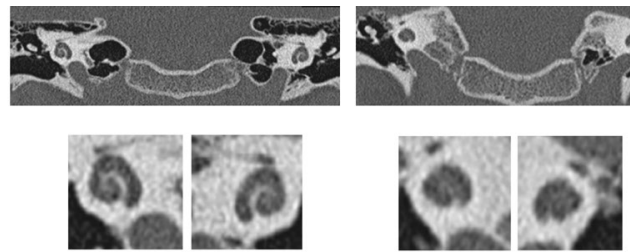

Control

Patient 1
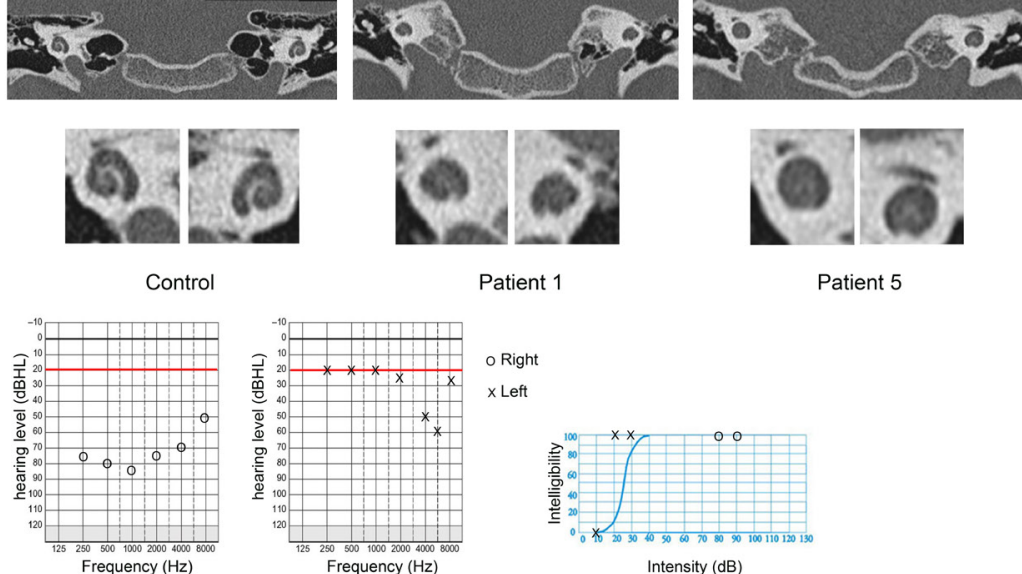

o Right

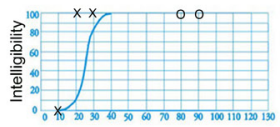

Intensity (AB)

Patient 1

C
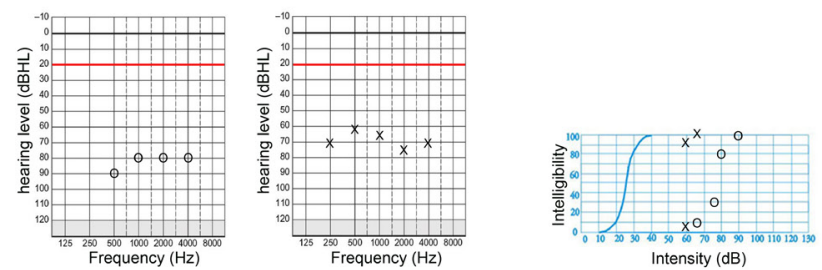

Intensity (dB)

Patient 5

D

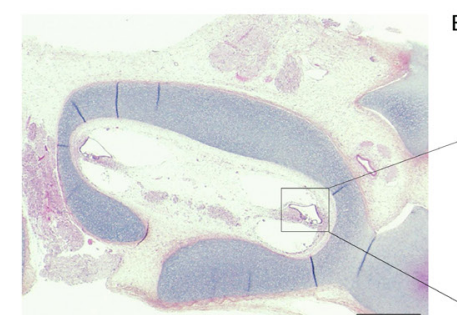

E
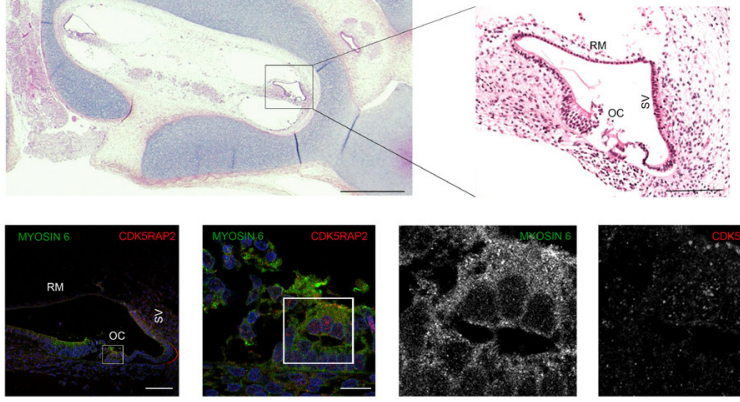

G
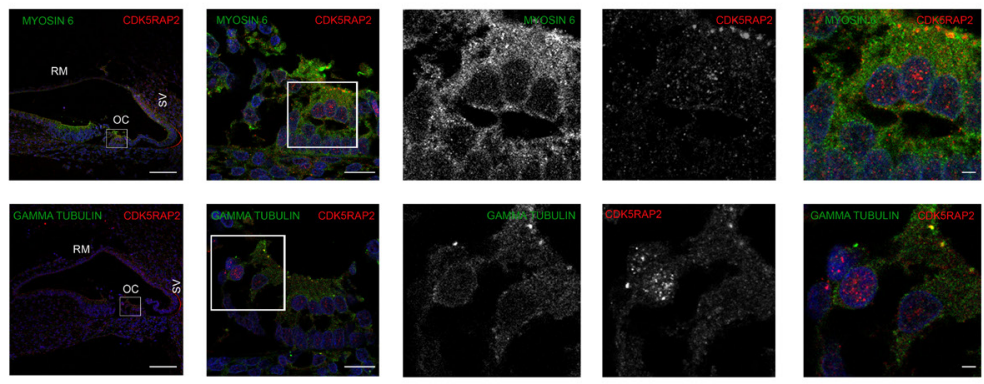

INNER EAR
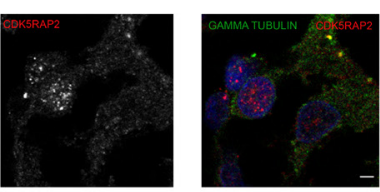

Figure 4

Figure 4 Congenital inner ear malformation responsible for progressive deafness in patients with CDK5RAP2 variants. (A) Temporal bone coronal CT scan images in patient 1 and 5 showing small cochlea with no visibility of the interscalar septa at the apical turn of the cochlea and a confluence of middle and apical turns of the cochlea, evocative of an incomplete partition type II according to Sennaroglu classification. (B, C) Tonal and vocal audiograms of patients 1 (B) and 5 (C). Circles and X symbolise joint air and bone-conducted hearing thresholds, respectively for right and left ears. (B) On the right ear, the ascending curve corresponds to a severe hearing loss whereas the left ear demonstrates a normal hearing threshold for conversational frequencies associated with a scotoma at $6000 \mathrm{~Hz}$. (C) The mean hearing threshold of $80 \mathrm{~dB}$ on the right ear and $70 \mathrm{~dB}$ on the left ear indicate a bilateral hearing loss. (D, E) Horizontal section of temporal bone (D) of a control fetus at WG12 stained by H\&E and high magnification on the cochlea (E) highlighting the structure of a normal fetal cochlea. RM, Reissler's membrane; OC, organ of Corti; SV, stria vascularis. Scale bars: $25 \mathrm{~mm}(\mathrm{D}), 500 \mu \mathrm{m}$ (E). (F, G) Immunohistochemistry in the adjacent section of the cochlea of the control fetus at WG12 shown in (D). White squares indicate regions of the cochlea that are shown in higher magnification in the right part of the panel. (F) Co-labelling of CDK5RAP2 (red) and myosin VI (green, that stains the outer hair cells of the cochlea) and DAPI (blue) showing that CDK5RAP2 is expressed in myosin VI positive cells at the apical pole of outer hair cells. (G) Co-labelling of CDK5RAP2 (red) and gamma-tubulin (green, that stains the pericentriolar material at the centrosome) demonstrating that CDK5RAP2 is localised at the centrosome of the outer hair cells of the cochlea. Scale bars: $90 \mu \mathrm{m}$ (first left panel), $15 \mu \mathrm{m}$ (second left panel), $15 \mu \mathrm{m}$ (right panel). 
not observed in our patients such as an absence of the septum pellucidum, optic pathway hypoplasia, hippocampal dysgenesis. ${ }^{32}{ }^{37}$ However, IHA may also occur as an isolated asymptomatic feature. ${ }^{32}$ At their last examination, the children of our series did not exhibit any obvious endocrine disorder attributable to the hypothalamic defect: growth was within the normal range for weight and height; no diabetes insipidus or high blood pressure was noted. Although no micropenis was detected, tracking puberty onset would be relevant. Interestingly, patients 1 and 4 showed excessive weight gain (after age 8 and 9, respectively). During the second decade of life, we propose to assess energy metabolism in these patients.

PM and HPE have already been associated in patients carrying variants in the MCPH7 gene STIL. ${ }^{38}$ These patients exhibit a mild lobar form of HPE and PM with gyral simplification and interhemispheric cysts. This suggests that, as for STIL, CDK5RAP2 can be added to the list of genes causing a forme fruste of HPE in humans.

\section{CDK5RAP2 and ear development}

We show here that CDK5RAP2 loss of function affects the development of extracortical regions and results in a broader phenotype than just microcephaly. This observation is consistent with the pattern of expression of CDK5RAP2, which encompasses the cortical VZ and subventricular zones and the spiral organ of Corti, and indicates that this centrosomal protein is critical to the development and maintenance of neurosensory functions.

Malformations of the inner ear are found in $30 \%-40 \%$ of children with SNHL on imaging (CT, MRI). ${ }^{33} 3940$ Incomplete partition of the cochlea type $\mathrm{II}^{34}$ refers to a cochlea that has a normal basal turn but a cystic apex with hypoplasia of the modiolus and absence of the interscalar septum. This malformation was obvious in all examined patients. Patient 2 also showed a dilated vestibule and vestibular aqueduct enlargement (Mondini dysplasia). Incomplete partition of the cochlea type II is a congenital cause of sensorineural hearing loss. This cochlear malformation typically occurs during WG7. ${ }^{41}$ Hearing loss may be mild to profound and must be evaluated with systematic audiometry. As CDK5RAP2 variants described in the present study have not been reported previously, one cannot rule out the possibility that the associated neurosensory impairments are variantspecific. However, hearing loss has been occasionally mentioned in previous CDK5RAP2 patients carrying other variants ${ }^{1926}$ and our systematic study suggests that the neurosensory defects are likely constitutive of the CDK5RAP2 phenotype and may have been overlooked in previously reported cases.

The most common aetiology of Mondini dysplasia is a variation in the SLC26A4 gene involved in Pendred syndrome ${ }^{42} 43$ and in a non-syndromic hearing loss, ${ }^{44}$ but variants in $>100$ genes cause severe congenital or progressive hearing loss. ${ }^{45}$ Genes involved in genetic SNHL encode proteins playing a role in gene regulation, fluid homeostasis, synaptic transmission and hair cell and neuronal maturation, and in stereocilia function. ${ }^{45}$ To date, no interaction between such proteins and CDK5RAP2 has been reported. In humans, the cochlea develops between WG6-7 and 10-12, and the vestibule between WG9 and $13,{ }^{41}$ that is, at the beginning of neurogenesis. It has been shown that the brain volume reduction related to Cdk5rap2-deficient mice is due to reduced neural progenitor proliferation, cell death and early neuronal differentiation during neurogenesis. ${ }^{15}$ It is thus possible that the observed simplification of the cochlear spiral also reflects defective proliferation or cell death leading to a depletion of the pool of progenitors and the early differentiation of the cochlear epithelium. Given that hearing loss was not congenital and was identified when the youngest patient was 6 years of age, we recommend that audiograms be performed systematically at the time of diagnosis, and possibly, repeated on a yearly basis. Neurosensory management of these patients is crucial as it considerably impacts communication, learning and integration abilities.

\section{CDK5RAP2 and eye development}

PM is not commonly associated with microphthalmia except in specific syndromes such as Warburg-Micro syndrome (\#600118，RAB3GAP1，\#614225，RAB3GAP2，\#614222, RAB18, \#615623, TBC1D20), microcephaly and chorioretinopathy type 3 (\#616335, TUBGCP4 ${ }^{45}$ ) or type 6 (\#251270, TUBGCP $6^{46}$ ) or microcephaly with or without chorioretinopathy, lymphoedema and mental retardation (\#152950, KIF11 $\left.{ }^{47}\right)$. In the present study, we have shown that microphthalmia is a cardinal feature of the CDK5RAP2-associated phenotype, and confirms in humans what Zaqout et al have recently shown in Cdk5rap2 mutant mice (an/an). ${ }^{48}$ More surprising were the retinal pigmentation changes found in all the patients. Retinal hyperpigmentation could be related to skin hyperpigmentation spots. Hypopigmented spots that are hyperautofluorescent are reminiscent of lipofuscin deposits/accumulation in the retinal pigmentary epithelium (RPE). No functional consequences on visual acuity or ERG were noticed. OCT was normal for both patients tested, suggesting that lipofuscin accumulation does not alter the RPE-photoreceptor layer. Our patients still being children, their ophthalmological status obviously needs to be reassessed to check whether lipofuscin deposits are stable or increase with time and/or impact visual function. These retinal pigmentation changes do not resemble the well-characterised chorioretinopathies associated with microcephaly such as those caused by PLK4, TUBGCP6 (\#25127046), TUBGC4 (\#616335 ${ }^{45}$ ) or KIF11 $\left(\# 152950^{47}\right)$ variants. We propose that this new entity, which resembles that described by Abdel-Saam et al prior to gene identification ${ }^{49}$ may be related to CDK5RAP2 variants, because it is present in all patients of the present series.

\section{CONCLUSION}

Overall, our findings extend the phenotype associated with CDK5RAP2 microcephaly and indicate that MCPH3 is distinct from other MCPH by its association with neurosensory impairment. These results shed new light on the role of CDK5RAP2 in brain, ear and eye development and maturation.

\section{Author affiliations}

'Département de Génétique, APHP, Hopital Robert Debré, 75019 Paris, France ${ }^{2}$ Service des Explorations Fonctionnelles, APHP, Hopital Robert Debré, 75019 Paris, France

${ }^{3}$ Service d'Ophtalmologie, APHP, Hopital Robert Debré, 75019 Paris, France ${ }^{4}$ Service de Radiologie Pédiatrique, APHP, Hopital Robert Debré, 75019 Paris, France ${ }^{5}$ Institute of Medical Genetics, University of Zurich, Schlieren-Zurich, Switzerland

${ }^{6}$ Université de Paris, NeuroDiderot, Inserm, F-75019 Paris, France

${ }^{7}$ Service d'Anatomopathologie, Hopital Jean Verdier, APHP, Bondy, France

${ }^{8}$ Université Paris 13, 93140 Bondy, France

${ }^{9}$ Service d'ORL, APHP, Hopital Robert Debré, 75019 Paris, France

${ }^{10}$ Service de Foetopathologie, APHP, Hopital Robert Debré, 75019 Paris, France ${ }^{11}$ CRMR déficiences intellectuelles de causes rares, Département de génétique, Sorbonne Université, APHP, Hôpital Trousseau, 75012 Paris, France

${ }^{12}$ Service de Neuropédiatrie, APHP, Hopital Trousseau, 75012 Paris, France

${ }^{13}$ Département de Génétique, APHP, Hopital La Pitié-Salpetriere, 75013 Paris, France

${ }^{14}$ Service de Génétique Médicale, CHU de Strasbourg, Hopital de Hautepierre, 67200

Strasbourg, France

${ }^{15}$ Service d'Ophtalmologie, APHP, Hopital Trousseau, 75012 Paris, France

${ }^{16}$ Service des Explorations Fonctionnelles, APHP, Hopital Lariboisière, 75010 Paris, France 
${ }^{17}$ Universita Cattolica Sacro Cuore Istituto di Medicina Genomica, Roma, Italy

${ }^{18}$ Fondazione Policlinico A. Gemelli IRCCS, Roma, Italy

${ }^{19}$ Unité d'Epidémiologie Clinique, APHP, Hopital Robert Debré, 75019 Paris, France

${ }^{20}$ Université de Paris, Centre d'Investigation Clinique, CIC 1426, INSERM, APHP,

Hopital Robert Debré, 75019 Paris, France

${ }^{21}$ Center for Developing Brain, King's College, St. Thomas' Campus, London, United Kingdom

${ }^{22}$ European Reference Network ERN ITHACA, 75019 Paris, France

${ }^{23}$ Service de Neuropédiatrie, APHP, Hopital Robert Debré, 75019 Paris, France

Acknowledgements The authors would like to thank all patients and their family. The authors would like to thank the $\mathrm{CIC}$ team (CIC 1426, Inserm) at Robert Debré Hospital in Paris who organised the families' visit and ensured the implementation of the clinical research protocol. The authors would also like to thank Dr Sowmyalakshmi Rasika for relevant comments and language editing during the preparation of this manuscript.

Contributors HN analysed and interpreted all clinical data. LV and NT analysed the ocular and ENT phenotypes, respectively for all patients with the help of MM. ME analysed brain MRI and temporal bone CT scan for all patients. HN, LV, NT and ME helped writing the manuscript. AE performed the neuropsychological assessment for all patients. KS, AA, MLM, DH, YA and MZ were involved in patient recruitment and clinical management. SGC and FK conducted the research protocol. PL and FG performed the immunostaining in human tissues. VEG, AV and PG revised and edited the manuscript. SD and AR analysed and interpreted NGS data and performed segregation analysis. SP conceived the study, interpreted the results and wrote the manuscript.

Funding This work was supported by the Délégation à la Recherche Clinique et à I'Innovation de l'Assistance Publique Hopitaux de Paris, the Institut National pour la Santé et la Recherche Médicale (Inserm), the Université Paris 7, the Centre National de la Recherche Scientifique (CNRS), the DHU PROTECT, the Programme Hospitalier de Recherche Clinique (PHRC, grant agreement nº P100128/IDRCB: 2010-A0148138), by ERA-NET grant 'Euromicro' (ANR-13-RARE-0007-01, ANR-16-CE16-0024-01 to SP, AV, VE, SD and PG and SNF 31ER30 154238 to AR) and radiz-Rare Disease Initiative Zurich, clinical research priority programme, University of Zurich.

Competing interests None declared.

Patient consent for publication Not required.

Ethics approval The trial was approved by the National Ethics Committee (Comite de Protection des Personnes (CPP) Ile-de-France II).

Provenance and peer review Not commissioned; externally peer reviewed.

Data availability statement Data are available on reasonable request. Data used in the manuscript are available by request to the authors.

ORCID iDs

Marcella Zollino http://orcid.org/0000-0003-4871-9519

Anita Rauch http://orcid.org/0000-0003-2930-3163

Sandrine Passemard http://orcid.org/0000-0002-0242-4566

\section{REFERENCES}

1 Kaindl AM, Passemard S, Kumar P, Kraemer N, Issa L, Zwirner A, Gerard B, Verloes A, Mani $S$, Gressens P. Many roads lead to primary autosomal recessive microcephaly. Prog Neurobiol 2010;90:363-83.

2 Thornton GK, Woods CG. Primary microcephaly: do all roads lead to Rome? Trends Genet 2009:25:501-10.

3 Verloes A, Drunat S, Gressens P, Passemard S. Primary Autosomal Recessive Microcephalies and Seckel Syndrome Spectrum Disorders. In: Pagon RA, Adam MP, Ardinger HH, Wallace SE, Amemiya A, Bean LJH, Stephens K, eds. GeneReviews 2013. (NBK9587 [bookaccession]). Seattle, 1993.

4 Izumi K, Brett M, Nishi E, Drunat S, Tan E-S, Fujiki K, Lebon S, Cham B, Masuda K, Arakawa M, Jacquinet A, Yamazumi Y, Chen S-T, Verloes A, Okada Y, Katou Y, Nakamura T, Akiyama T, Gressens P, Foo R, Passemard S, Tan E-C, El Ghouzzi V, Shirahige K. ARCN1 mutations cause a recognizable craniofacial syndrome due to COPI-mediated transport defects. Am J Hum Genet 2016:99:451-9.

5 Lines MA, Huang L, Schwartzentruber J, Douglas SL, Lynch DC, Beaulieu C, GuionAlmeida ML, Zechi-Ceide RM, Gener B, Gillessen-Kaesbach G, Nava C, Baujat G, Horn D, Kini U, Caliebe A, Alanay Y, Utine GE, Lev D, Kohlhase J, Grix AW, Lohmann DR, Hehr U, Böhm D, Majewski J, Bulman DE, Wieczorek D, Boycott KM, FORGE Canada Consortium. Haploinsufficiency of a spliceosomal GTPase encoded by Eftud2 causes mandibulofacial dysostosis with microcephaly. Am \& Hum Genet 2012:90:369-77.

6 Ostergaard P, Simpson MA, Mendola A, Vasudevan P, Connell FC, van Impel A, Moore AT, Loeys BL, Ghalamkarpour A, Onoufriadis A, Martinez-Corral I, Devery S, Leroy JG, van Laer L, Singer A, Bialer MG, McEntagart M, Quarrell O, Brice G, Trembath RC, Schulte-Merker S, Makinen T, Vikkula M, Mortimer PS, Mansour S, Jeffery S. Mutations in KIF11 cause autosomal-dominant microcephaly variably associated with congenital lymphedema and chorioretinopathy. Am J Hum Genet 2012;90:356-62.
7 Boonsawat P, Joset P, Steindl K, Oneda B, Gogoll L, Azzarello-Burri S, Sheth F, Datar C, Verma IC, Puri RD, Zollino M, Bachmann-Gagescu R, Niedrist D, Papik M, FigueiroSilva J, Masood R, Zweier M, Kraemer D, Lincoln S, Rodan L, Passemard S, Drunat S, Verloes A, Horn AHC, Sticht H, Steinfeld R, Plecko B, Latal B, Jenni O, Asadollahi R, Rauch A, Undiagnosed Diseases Network (UDN). Elucidation of the phenotypic spectrum and genetic landscape in primary and secondary microcephaly. Genet Med 2019;21:2043-58.

8 Jayaraman D, Bae B-I, Walsh CA. The genetics of primary microcephaly. Annu Rev Genomics Hum Genet 2018;19:177-200.

9 Bond J, Roberts E, Springell K, Lizarraga SB, Lizarraga S, Scott S, Higgins J, Hampshire DJ, Morrison EE, Leal GF, Silva EO, Costa SMR, Baralle D, Raponi M, Karbani G, Rashid Y, Jafri H, Bennett C, Corry P, Walsh CA, Woods CG. A centrosomal mechanism involving CDK5RAP2 and CENPJ controls brain size. Nat Genet 2005;37:353-5.

10 Graser S, Stierhof Y-D, Nigg EA. Cep68 and Cep215 (CDK5RAP2) are required for centrosome cohesion. J Cell Sci 2007:120:4321-31.

11 Barr AR, Kilmartin JV, Gergely F. Cdk5Rap2 functions in centrosome to spindle pole attachment and DNA damage response. J Cell Biol 2010;189:23-39.

12 Fong K-W, Choi Y-K, Rattner JB, Qi RZ. Cdk5Rap2 is a pericentriolar protein that functions in centrosomal attachment of the $\gamma$-tubulin ring complex. Mol Biol Cell 2008; 19:115-25

13 Megraw TL, Sharkey JT, Nowakowski RS. Cdk5Rap2 exposes the centrosomal root of microcephaly syndromes. Trends Cell Biol 2011;21:470-80.

14 Buchman JJ, Durak O, Tsai L-H. Aspm regulates Wnt signaling pathway activity in the developing brain. Genes Dev 2011;25:1909-14.

15 Lizarraga SB, Margossian SP, Harris MH, Campagna DR, Han A-P, Blevins S, Mudbhary R, Barker JE, Walsh CA, Fleming MD. Cdk5Rap2 regulates centrosome function and chromosome segregation in neuronal progenitors. Development 2010;137:1907-17.

16 Issa L, Kraemer N, Rickert CH, Sifringer M, Ninnemann O, Stoltenburg-Didinger G, Kaindl AM. Cdk5Rap2 expression during murine and human brain development correlates with pathology in primary autosomal recessive microcephaly. Cereb Cortex 2013;23:2245-60.

17 Abdullah U, Farooq M, Mang Y, Marriam Bakhtiar S, Fatima A, Hansen L, Kjaer KW, Larsen LA, Faryal S, Tommerup N, Mahmood Baig S. A novel mutation in CDK5RAP2 gene causes primary microcephaly with speech impairment and sparse eyebrows in a consanquineous Pakistani family. Eur J Med Genet 2017:60:627-30.

18 Ahmad I, Baig SM, Abdulkareem AR, Hussain MS, Sur I, Toliat MR, Nürnberg G, Dalibor N, Moawia A, Waseem SS, Asif M, Nagra H, Sher M, Khan MMA, Hassan I, Rehman SU, Thiele H, Altmüller J, Noegel AA, Nürnberg P. Genetic heterogeneity in Pakistani microcephaly families revisited. Clin Genet 2017;92:62-8.

19 Alfares A, Alhufayti I, Alsubaie L, Alowain M, Almass R, Alfadhel M, Kaya N, Eyaid W. A new association between CDK5RAP2 microcephaly and congenital cataracts. Ann Hum Genet 2018;82:165-70.

20 Hassan MJ, Khurshid M, Azeem Z, John P, Ali G, Chishti MS, Ahmad W. Previously described sequence variant in CDK5RAP2 gene in a Pakistani family with autosomal recessive primary microcephaly. BMC Med Genet 2007:8:58.

21 Issa L, Mueller K, Seufert K, Kraemer N, Rosenkotter H, Ninnemann O, Buob M, Kaindl AM, Morris-Rosendahl DJ. Clinical and cellular features in patients with primary autosomal recessive microcephaly and a novel CDK5RAP2 mutation. Orphanet J Rare Dis 2013:8:59.

22 Jouan L, Ouled Amar Bencheikh B, Daoud H, Dionne-Laporte A, Dobrzeniecka S, Spiegelman D, Rochefort D, Hince P, Szuto A, Lassonde M, Barbelanne M, Tsang WY, Dion PA, Théoret $H$, Rouleau GA, Wy T, Ga R. Exome sequencing identifies recessive CDK5RAP2 variants in patients with isolated agenesis of corpus callosum. Eur J Hum Genet 2016:24:607-10.

23 Lancaster MA, Renner M, Martin C-A, Wenzel D, Bicknell LS, Hurles ME, Homfray T, Penninger JM, Jackson AP, Knoblich JA. Cerebral organoids model human brain development and microcephaly. Nature 2013;501:373-9.

24 Li MH, Arndt K, Das S, Weiss EM, Wu Y, Gwal K, Shekdar KV Zackai EH. Compound heterozygote CDK5RAP2 mutations in a Guatemalan/Honduran child with autosomal recessive primary microcephaly, failure to thrive and speech delay. Am J Med Genet $A$ 2015;167:1414-7.

25 Moynihan L, Jackson AP, Roberts E, Karbani G, Lewis I, Corry P, Turner G, Mueller RF, Lench NJ, Woods CG. A third novel locus for primary autosomal recessive microcephaly maps to chromosome 9q34. Am J Hum Genet 2000;66:724-7.

26 Pagnamenta AT, Murray JE, Yoon G, Sadighi Akha E, Harrison V, Bicknell LS, Ajilogba K, Stewart H, Kini U, Taylor JC, Keays DA, Jackson AP, Knight SJL. A novel nonsense CDK5RAP2 mutation in a Somali child with primary microcephaly and sensorineural hearing loss. Am J Med Genet A 2012;158A:2577-82.

27 Sukumaran SK, Stumpf M, Salamon S, Ahmad I, Bhattacharya K, Fischer S, Müller R, Altmüller J, Budde B, Thiele H, Tariq M, Malik NA, Nürnberg P, Baig SM, Hussain MS, Noegel AA. Cdk5Rap2 interaction with components of the Hippo signaling pathway may play a role in primary microcephaly. Mol Genet Genomics 2017;292:365-83.

28 Tan CA, del Gaudio D, Dempsey MA, Arndt K, Botes S, Reeder A, Das S. Analysis of ASPM in an ethnically diverse cohort of 400 patient samples: perspectives of the molecular diagnostic laboratory. Clin Genet 2014;85:353-8.

29 Yigit G, Brown KE, Kayserili H, Pohl E, Caliebe A, Zahnleiter D, Rosser E, Bögershausen N, Uyguner ZO, Altunoglu U, Nürnberg G, Nürnberg P, Rauch A, Li Y, Thiel CT, Wollnik 
B. Mutations in CDK5RAP2 cause Seckel syndrome. Mol Genet Genomic Med 2015;3:467-80

30 Létard P, Drunat S, Vial Y, Duerinckx S, Ernault A, Amram D, Arpin S, Bertoli M, Busa T, Ceulemans B, Desir J, Doco-Fenzy M, Elalaoui SC, Devriendt K, Faivre L, Francannet C, Geneviève D, Gérard M, Gitiaux C, Julia S, Lebon S, Lubala T, Mathieu-Dramard M, Maurey H, Metreau J, Nasserereddine S, Nizon M, Pierquin G, Pouvreau N, RivierRingenbach C, Rossi M, Schaefer E, Sefiani A, Sigaudy S, Sznajer Y, Tunca Y, Guilmin Crepon S, Alberti C, Elmaleh-Bergès M, Benzacken B, Wollnick B, Woods CG, Rauch A, Abramowicz M, El Ghouzzi V, Gressens P, Verloes A, Passemard S. Autosomal recessive primary microcephaly due to ASPM mutations: an update. Hum Mutat 2018:39:319-32.

31 Baala L, Briault S, Etchevers HC, Laumonnier F, Natiq A, Amiel J, Boddaert N, Picard C, Sbiti A, Asermouh A, Attié-Bitach T, Encha-Razavi F, Munnich A, Sefiani A, Lyonnet S. Homozygous silencing of T-box transcription factor EOMES leads to microcephaly with polymicrogyria and corpus callosum agenesis. Nat Genet 2007;39:454-6.

32 Ahmed FN, Stence NV, Mirsky DM. Asymptomatic Interhypothalamic adhesions in children. AJNR Am I Neuroradiol 2016;37:726-9.

33 Teissier N, Van Den Abbeele T, Sebag G, Elmaleh-Berges M. Computed tomography measurements of the normal and the pathologic cochlea in children. Pediatr Radiol 2010;40:275-83.

34 Sennaroglu L, Saatci I. Unpartitioned versus incompletely partitioned cochleae: radiologic differentiation. Otol Neurotol 2004;25:520-9.

35 Gilmore EC, Walsh CA. Genetic causes of microcephaly and lessons for neuronal development. Wiley Interdiscip Rev Dev Biol 2013;2:461-78.

36 Passemard S, Perez F, Colin-Lemesre E, Rasika S, Gressens P, El Ghouzzi V. Golgi trafficking defects in postnatal microcephaly: The evidence for "Golgipathies". Prog Neurobiol 2017;153:46-63.

37 Whitehead MT, Vezina G. Interhypothalamic adhesion: a series of 13 cases. AJNR Am J Neuroradiol 2014;35:2002-6.

38 Kakar N, Ahmad J, Morris-Rosendahl DJ, Altmüller J, Friedrich K, Barbi G, Nürnberg P, Kubisch C, Dobyns WB, Borck G. Stil mutation causes autosomal recessive microcephalic lobar holoprosencephaly. Hum Genet 2015;134:45-51.

39 Paul A, Marlin S, Parodi M, Rouillon I, Guerlain J, Pingault V, Couloigner V, Garabedian EN, Denoyelle F, Loundon N. Unilateral sensorineural hearing loss: medical context and etiology. Audiol Neurootol 2017;22:83-8.

40 Wentland CJ, Ronner EA, Basonbul RA, Pinnapureddy S, Mankarious L, Keamy D, Lee DJ, Cohen MS. Utilization of diagnostic testing for pediatric sensorineural hearing loss. Int J Pediatr Otorhinolaryngol 2018;111:26-31.
41 Lim R, Brichta AM. Anatomical and physiological development of the human inner ear. Hear Res 2016:338:9-21.

42 Everett LA, Glaser B, Beck JC, Idol JR, Buchs A, Heyman M, Adawi F, Hazani E, Nassir E, Baxevanis AD, Sheffield VC, Green ED. Pendred syndrome is caused by mutations in a putative sulphate transporter gene (PDS). Nat Genet 1997;17:411-22.

43 Usami S, Abe S, Weston MD, Shinkawa H, Van Camp G, Kimberling WJ. Non-Syndromic hearing loss associated with enlarged vestibular aqueduct is caused by PDS mutations. Hum Genet 1999;104:188-92.

44 Lenz DR, Avraham KB. Hereditary hearing loss: from human mutation to mechanism. Hear Res 2011:281:3-10.

45 Scheidecker S, Etard C, Haren L, Stoetzel C, Hull S, Arno G, Plagnol V, Drunat S, Passemard S, Toutain A, Obringer C, Koob M, Geoffroy V, Marion V, Strähle U, Ostergaard P, Verloes A, Merdes A, Moore AT, Dollfus H. Mutations in TUBGCP4 alter microtubule organization via the $\gamma$-tubulin ring complex in autosomal-recessive microcephaly with chorioretinopathy. Am J Hum Genet 2015;96:666-74.

46 Martin C-A, Ahmad I, Klingseisen A, Hussain MS, Bicknell LS, Leitch A, Nürnberg G, Toliat MR, Murray JE, Hunt D, Khan F, Ali Z, Tinschert S, Ding J, Keith C, Harley ME, Heyn P, Müller R, Hoffmann I, Cormier-Daire V, Dollfus H, Dupuis L, Bashamboo A, McElreavey K, Kariminejad A, Mendoza-Londono R, Moore AT, Saggar A, Schlechter C, Weleber R, Thiele H, Altmüller J, Höhne W, Hurles ME, Noegel AA, Baig SM, Nürnberg P, Jackson AP. Mutations in PLK4, encoding a master regulator of centriole biogenesis, cause microcephaly, growth failure and retinopathy. Nat Genet 2014;46:1283-92.

47 Robitaille JM, Gillett RM, LeBlanc MA, Gaston D, Nightingale M, Mackley MP, Parkash S, Hathaway J, Thomas A, Ells A, Traboulsi El, Héon E, Roy M, Shalev S, Fernandez CV, MacGillivray C, Wallace K, Fahiminiya S, Majewski J, McMaster CR, Bedard K. Phenotypic overlap between familial exudative vitreoretinopathy and microcephaly, lymphedema, and chorioretinal dysplasia caused by KIF11 mutations. JAMA Ophthalmol 2014;132:1393-9.

48 Zaqout S, Ravindran E, Stoltenburg-Didinger G, Kaindl AM. Congenital microcephalylinked CDK5RAP2 affects eye development. Ann Hum Genet 2019. doi:10.1111/ ahg.12343. [Epub ahead of print: 29 Jul 2019].

49 Abdel-Salam GM, Vogt G, Halász A, Czeizel A. Microcephaly with normal intelligence, and chorioretinopathy. Ophthalmic Genet 1999;20:259-64.

50 Garel C, Cont I, Alberti C, Josserand E, Moutard ML, Ducou le Pointe H. Biometry of the corpus callosum in children: MR imaging reference data. AJNR Am J Neuroradiol 2011;32:1436-43. 